\title{
Çilekte bor gübrelemesinin bozuk şekilli meyve oluşumunun önlenmesi ve yaprak mineral içerikleri üzerine etkisi
}

\author{
Faruk ÖZKUTLU1 ${ }^{1}$ Özlem ETE ${ }^{1}$, Mehmet AKGÜN¹, Fatmagül AKDİN¹, Yusuf TUTUŞ², Bayram ÖZCAN¹
}

${ }^{1}$ Ordu Üniversitesi, Ziraat Fakültesi, Toprak Bilimi ve Bitki Besleme Bölümü, ORDU

${ }^{2}$ Sabancı Üniversitesi, Mühendislik ve Doğa Bilimleri Fakültesi, Tuzla-İSTANBUL

Alınış tarihi: 17 Nisan 2017, Kabul tarihi: 12 Temmuz 2017

Sorumlu yazar: Faruk ÖZKUTLU, e-posta:farukozkutlu@hotmail.com

$\ddot{0} \mathbf{z}$

Bor (B) bitkilerin büyüme ve gelişmeleri için gerekli mikroelementtir. Borun bitkideki noksanlık ve fazlalık aralıkları birbirine çok yakındır. Bor gübrelemesinde bitkinin isteği dikkate alınmalıdır. Çileklerde bozuk şekilli meyve oluşumları birçok faktörle ilişkilidir. Bozuk șekilli meyve oluşumunun yetersiz tozlanma ve döllenmeden kaynaklandığı ve bu durumun bor beslenmesiyle ilişkili olduğu bilinmektedir. Genellikle çilek üretiminde bitkiler tam beslenemediğinde elde edilen meyvelerin bir bölümünün bozuk şekilli elde edilmesi ekonomik kayıplara neden olmaktadır. Özellikle çilek bitkisinde B gübre uygulamalarıyla meyve kalitesinin artırılması mümkündür. $\mathrm{Bu}$ araștırmada sera koşullarında B noksan bir toprak kullanılarak topraktan artan dozlarda $\left(0,2.5,5.0,10.0 \mathrm{mg} \mathrm{B} \mathrm{kg}^{-1}\right)$ bor gübrelemesinin Camarosa ve Sweet Charlie çilek çeşitlerinin bozuk şekilli meyve oluşumları, yaprak mineral element konsantrasyonu ve verim üzerine etkileri belirlenmiştir. Hiç B gübrelemesi yapılmayan kontrol bitkilerinde bozuk şekilli meyvelerin oluştuğu ve ekonomik kayıpların olduğu tespit edilmiştir. Düşük doz (2,5 mg B kg-1 toprak) B gübrelemesinin bozuk şekilli meyve oluşumunu azalttığl, yüksek doz $\left(10,0 \mathrm{mg} \mathrm{B} \mathrm{kg}^{-1}\right.$ toprak) B gübrelemesinin toksik etki ettiği ve oluşan meyvelerin küçük ve meyve ağırlığının düşük olduğu bulunmuştur. Ayrıca, düşük doz $\left(2,5 \mathrm{mg} \mathrm{B} \mathrm{kg}^{-1}\right.$ toprak) B gübrelemesinin çilek yapraklarının toplam Azot $(\mathrm{N})$ ve kalsiyum (Ca) miktarında azalmaya neden olmasına karşın fosfor (P), potasyum (K), mangan $(\mathrm{Mn})$, çinko $(\mathrm{Zn})$ ve bakır $(\mathrm{Cu})$ konsatrasyonunu arttırdığı saptanmıştır. $\mathrm{Bu}$ araştırmadan elde edilen sonuçlara göre, B bakımından yetersiz olan topraklarda düşük miktarda B gübrelemesiyle çilek meyvesinde bozuk şekilli oluşumların azaltılarak ekonomik kayıpların minimize edilmesi ve meyve kalitesinin arttırılmasının mümkün olabileceği ortaya konmuștur.

Anahtar kelimeler: Çilek, bozuk şekilli meyve, bor

\section{Boron fertilization effects on strawberry plant for preventing decomposed shaped fruit generation and on mineral content of leaves}

\begin{abstract}
Boron (B) is a needed microelement for plant growth and development. The deficiency and overdose distances of B in plant are very close. The plant need should be counted in B fertilization. The decomposed shaped fruit generations in strawberry are related too many factors. Decomposed shaped fruits are composed in state of lack pollination and this situation is known that is related to B fertilization. Generally in strawberry production, due to lack nutrition of plants, some part of fruits are obtained decomposed shaped and it causes economic losses. Specially, in strawberry plant, the fruit quality increase is possible with boron fertilizer applications. In this study, a boron deficient soil was selected and under greenhouse conditions $(0,2.5$, 5.0, $10.0 \mathrm{mg} \mathrm{B} \mathrm{kg}^{-1}$ ) dosages effects were determined on decomposed shaped fruit generations, leaf mineral element concentrations and yield at Camarosa and Sweet Charlie species. In control
\end{abstract}


plants that has no boron fertilization, decomposed shaped fruits generation and due to this economic losses were determined. It was determined in the study that low dosage $\left(2,5 \mathrm{mg} \mathrm{B} \mathrm{kg}^{-1}\right.$ soil) boron fertilization decreases decomposed shaped fruit generation and high dosage (10,0 mg B kg-1 soil) boron fertilization has toxic effect on generating fruits as small and low weight of fruits. In addition to these, the low dosage $\left(2,5 \mathrm{mg} \mathrm{B} \mathrm{kg}^{-1}\right.$ soil) boron fertilization causes decreasing on $\mathrm{N}$ and $\mathrm{Ca}$ amounts of strawberry leafs however provides increasing on the concentration of phosphorus (P), potassium (K), manganese $(\mathrm{Mn})$, Zinc $(\mathrm{Zn})$ and Copper $(\mathrm{Cu})$ were determined. According to obtained results in this study, in the imperfect soils in terms of $B$, it is possible to decrease decomposed shaped generations on strawberry fruit, minimize economic losses and increase fruit quality were determined via low amount B fertilization.

Key words: Strawberry, disordered fruit, boron fertilizer

\section{Giriş}

Bor bitkiler için mutlak gerekli element olup noksanlığı durumunda bitkilerde yaygın olarak beslenme sorunlarına neden olmaktadır. Borun topraklarda noksan ve fazla olması bitki gelişmesini doğrudan etkileyen en önemli iki durumdur. Genellikle kurak ve yarı kurak bölgelerde B noksanlığından ziyade $\mathrm{B}$ toksisitesi görülmektedir. Ilıman bölgelerde özellikle fazla yağıșla B'un topraklardan kolayca yıkanıp uzaklaşması olmaktadır. Özellikle asit bölge topraklarında yaygın olarak yapılan kireçlemenin B'un yarayışlılığını azalttığı ve sıklıkla B noksanlığına neden olmaktadır. $\mathrm{Bu}$ nedenle B'un eksikliği ve fazla miktarda olmasıyla bitkilerin B beslenmesi olumsuz olarak etkilenmektedir. Bor'un bitkilerin beslenmesinde ve bitkilerde önemli fizyolojik süreçlerde rol'ü olmasından dolayı bitkilere bor uygulaması çalışmaları artan bir şekilde devam etmektedir. Son yıllarda dünya genelinde 80 'den fazla ülkede B uygulamalarının 132 bitki türünde B'lu gübre uygulamalarının sonucunda birçok bitkisel üründe pozitif etkilerinin elde edildiği bildirmiștir (Shorrocks, 1997; Brown ve ark., 2002). Özellikle asit bölge topraklarında yaygın olarak yapılan kireçlemenin borun yarayışlılığını azalttığı ve sıklıkla B noksanlı̆̆ına yol açtığı bilinmektedir. Bitkiler B'u pasif olarak $\left[\mathrm{B}(\mathrm{OH})_{3}\right]$ halinde ve az da olsa aktif olarak $\left(\mathrm{B}(\mathrm{OH})_{4}^{-}\right)$halinde alırlar. Borun bitkilerdeki hareketi oldukça düşüktür. Bor transpirasyona bağlı olarak taşındığı için genellikle bitkinin B kapsamı aşağıdan yukarıya doğru artış göstermektedir. B alımı, ortamdaki B miktarına ve transpirasyon oranına bağlıdır. Bor bitkide transpirasyon akışına göre ksilemde taşındığından yaprak uçları ve kenarlarında birikmektedir (Marschner, 1995). Bor eksikliği öncelikle büyüme noktalarına zarar verdiği için bitkilerde büyümenin yavaşlamasına neden olur. Bor noksanlığı altında yetiştirilen bitkilerin pazar değerinin yitirilmesinden kaynaklanan kayıplardan en fazla etkilenen çilek meyvesidir.

Çilek, farklı ekolojilerde yetişebilme yeteneğine sahip olan üzümsü meyve türlerindendir. Çileğin ticari anlamda yaygın olarak yetiştiren ülkeler arasında ABD, Türkiye, Avrupa, Güney ve Doğu Afrika ülkeleri, Yeni Zelanda, Avustralya ve Japonya yer almaktadır (FAO,2013). 2012 yılında en fazla çilek üretimi $A B D$ ve bunu takiben de Türkiye 353.173 ton üretimle ikinci sırada yer almıştır. Türkiye çilek üretimi bölge bazında incelendiğinde \% 47.54'ünü Marmara, \% 30.39'unu Akdeniz, \% 13.71'ini Ege Bölgesi karşılamaktadır (Anonim, 2012). Farklı bölgelerde yetiştirilebilen çilek fotoperiyod'a verdikleri tepkileri yönünden 3 grup altında değerlendirilir. Bunlar; kısa gün (Junebearing), uzun gün (Everbearing) ve nötr-gün (Day-neutral) olarak sinıflandırılmaktadır (Demirsoy ve ark., 2012). Stewart ve Folta (2010) bildirdiğine göre, kısa gün çileklerinin, günlük ışıklanmanın 10 saatten daha az olduğu kısa günlerde ve yaz sonu ile sonbahar başında çiçek tomurcuğu oluşturdukları bunu takiben de ilkbaharda meyve verdikleri bildirilmiştir.

Bor noksanlığı koşullarında yetiştirilen çileğin büyümesi ve kalitesi olumsuz etkilenmektedir. Çiçek tozunun çimlenme yeteneği bor mineralinin varlığıyla doğrudan ilişkili olup yeteri kadar bor minerali alamayan bitkilerde yeterli meyve tutumu ve gelişiminin sağlanamadığı bildirilmiştir (Gupta ve ark., 1985). Bor bitki için çok az düzeyde yeterli olmasına karşın belirli düzeyin altına düşmesi durumunda bitkide generatif ve vejetatif gelişme noksanlığı ortaya çıkar. Bor'un değişik bitkiler üzerine ve aynı türün çeşitleri üzerine etkileri de farklı olmaktadır.

$\mathrm{Bu}$ araştırmada, ülkemizde yaygın olarak üretimi yapılan kısa gün çilek çeşitlerinden Camarosa ve Sweet Charlie çeşitlerinin bor noksanlığı sahip bir toprakta yetiştirilmesi durumunda meyvelerde 
oluşan şekil bozukluğunun belirlenmesi ve bor uygulamasına verdikleri tepkiler araştırılmıştır.

\section{Materyal ve Metot}

\section{Denemede kullanılan toprak ve çilek çeşitleri}

Deneme, 2015 yılı Şubat-Mayıs döneminde Ordu Üniversitesi Ziraat Fakültesi Araştırma ve Uygulama Çiftliğinde sera koşullarında yapılmıştır. Araştırma tesadüf parselleri deneme desenine göre planlanmış ve 3 tekerrürlü olarak yürütülmüștür. Denemede, plastik baton tipi 10 nolu saksılar kullanılmış ve her saksıya 4 mm'lik elekten elenmiş hava kurusu $9 \mathrm{~kg}$ toprak ilave edilmiştir. Denemede $0.05 \mathrm{mg} \mathrm{kg}^{-1} \mathrm{~B}$ konsantrasyonuna sahip olan ve B bakımından noksan olan toprak kullanılmıştır (Çizelge 1). Sera koşullarında yürütülen denemede Camarosa ve Sweet Charlie kısa gün çilek çeşitleri kullanılmıştır.

Çilek çeşitlerinin frigo fideleri Ankara'da bulunan EKODOĞA firmasından temin edilmiștir.

Çizelge 1. Denemede kullanılan toprağın bazı fiziksel ve kimyasal analiz sonuçları

\begin{tabular}{ccc}
\hline & & Ortalama \\
\hline Tekstür & Tınlı \\
$\mathrm{EC}$ & $\mathrm{dS} \mathrm{m}{ }^{-1}$ & 0.11 \\
$\mathrm{pH}(1: 2.5)$ & & 5.3 \\
\hline $\mathrm{CaCO}_{3}$ & \multirow{2}{*}{0.96} \\
Organik madde & & 2.07 \\
\hline $\mathrm{P}$ & & 20 \\
$\mathrm{~K}$ & & 86 \\
$\mathrm{Ca}$ & & 3740 \\
$\mathrm{Mg}$ & $\mathrm{mg} / \mathrm{kg}$ & 1050 \\
$\mathrm{Fe}$ & 9.71 \\
$\mathrm{Cu}$ & 0.3 \\
$\mathrm{Mn}$ & & 8.68 \\
$\mathrm{Zn}$ & & 0.13 \\
$\mathrm{~B}$ & & 0.05 \\
\end{tabular}

\section{Saksı Denemesinin Yürütülmesi ve Hasadı}

Deneme saksılarına ekimden önce temel gübreleme için $\mathrm{Ca}\left(\mathrm{NO}_{3}\right) 2.4 \mathrm{H}_{2} \mathrm{O}$ formunda $200 \mathrm{mg} \mathrm{N} \mathrm{kg}-1$, $\mathrm{KH}_{2} \mathrm{PO}_{4}$ formunda $100 \mathrm{mg} \mathrm{P} \mathrm{kg}^{-1}$ (=125 $\mathrm{mg} \mathrm{K} \mathrm{kg}^{-1}$ ) dikim öncesinde çözelti şeklinde uygulanmıştır. Her saksıya Camarosa ve Sweet Charlie çilek çeşitlerinden 6 fide şaşırtılmıştır. Şaşırtılan fideler 3 yapraklı olduktan sonra tarım B (Suda Çözünebilir Bor: \% 20,8 Etidot-67: $\mathrm{Na}_{2} \mathrm{~B}_{8} \mathrm{O}_{13} .4 \mathrm{H}_{2} \mathrm{O}$ ) gübresinden kontrole ek olarak 2.5, 5.0 ve $10.0 \mathrm{mg} \mathrm{B} \mathrm{kg}^{-1}$ artan dozlarda saksılara çözelti şeklinde verilmiştir. Çilek bitkisi çiçeklenme görülmeye başladıktan sonra yaprak analizi için ara hasat yapılmıștır. Saksılarda her çeşitten 3 bitki kalacak şekilde seyreltilmiş ve meyve aşamasına kadar yetiştirilmiştir. Çileklerin büyümeleri süresince toprakların tarla kapasitesinin
\% 60-70'ine denk gelecek şekilde saksılara saf su verilmiştir. Çiçeklenme öncesi bitkilerin yeşil aksam hasadı simptomların şiddetine ve büyümede gerileme düzeyine bağlı olarak belirlenmiştir. Buna göre, bitkiler çiçeklenme öncesinde toprak seviyesinden $1 \mathrm{~cm}$ yukarıdan olacak şekilde hasadı yapılmıştır.

Toprak ve yaprak analizlerinin yapılması ve yöntemleri

\section{Toprak Analizleri}

Denemede kullanılan toprakta Bünye (Tekstür): Hidrometre yöntemine göre ;\% kum, kil ve silt toprak fraksiyonları belirlenmiştir (Bouyocous, 1951). Toprakta pH Tayini: Toprak pH (Toprak Reaksiyonu)'sının ölçümü için toprak/su 1:2.5 oranı kullanılarak yapılmıştır (Richards,1954). Toprakta EC Belirlenmesi: Toplam Tuz 1:2.5 toprak/su oranı süspansiyonunda EC-metre ile ölçülmüştür (Richards, 1954). Kireç $\left(\mathrm{CaCO}_{3}\right)$ : Toprak Kirec (CaCO3)'i ölçümü için 1:3 $\mathrm{HCl} / \mathrm{su}$ oranında \% değerleri belirlenmiştir (Allison ve Moodie, 1965) . Organik madde Walkey \& Black (1934) göre yapılmıștır. Bitkiye yarayışlı fosfor Bray ve Kurtz (1945) tarafından geliştirilen Bray ve Kurtz No:1 yöntemine göre yapılmıştır. Bitkiye yarayışlı potasyum, kalsiyum ve magnezyum, Pratt (1965) tarafından bildirildiği şekilde toprak örneği $1,0 \mathrm{~N}$ nötr (7.0) amonyum asetat ile ekstrakte edilerek süzükteki potasyum, kalsiyum ve magnezyum ICPOES cihazı ile belirlenmiştir (Boss ve Fredeen, 2004). Alınabilir demir, bakır, çinko ve mangan Lindsay ve Norvell (1978) yöntemine göre yapılmıştır. Toprakta sıcak su ile extrakte edilebilir B sıcak su yöntemine göre 0,01 $\mathrm{M} \mathrm{CaCl}_{2}$ ile ekstrakte edilen örneklerde bitkiye yarayışlı bor ICP-OES (Inductively Coupled Plasma-Optical Emission Spectrometry, Perkin Elmer Model DV 2100) cihazı ile saptanmıştır (Bingham, 1982).

\section{Bitki Analizleri}

Hasat edilen çilek yaprak örnekleri saf su ile yıkanıp, 48 saat süresince 65 0C'de kurutulmuştur. Kurutulan bitkilerin kuru ağırlıkları belirlenerek kuru madde verimleri tespit edilmiştir. Daha sonra agat değirmende ögütülmüştür. Ögütülen çilek yapraklarında toplam azot Kjeldahl yöntemine göre (Bremner, 1965); toplam P, K, Ca, Mg, Zn, Cu, Mn, Fe ve $\mathrm{B}$ konsantrasyonları mikrodalgada yaş yakma suretiyle hazırlanan süzükte ICP-OES (Inductively Coupled Plasma-Optical Emission Spectrometry, Varian PRO Vista) cihazı ile belirlenmiștir (Boss ve Fredeen, 2004). 


\section{Meyve Ölçümleri}

Meyve Ağırlığı (g) her tekerrürden alınan meyvelerin tamamı sayılarak tartılmış ve ortalama meyve ağırlığı g olarak tespit edilmiştir (Kaşka ve ark.,1986; Türemiş, 2003); Bitki Başına Verim (meyve sayısı/bitki) iki haftada bir 2 kez yapılan hasatta oluşan meyveler sayılarak kayıt altına alınmıștır (Türemiş, 2003).

\section{Sonuçlar ve Tartışma}

\section{Kuru madde verimi}

Sera koşullarında Camarosa ve Sweet Charlie çilek çeşitlerine artan dozlarda toprağa B uygulamasıyla bitki kuru madde veriminde farklılıkların olduğu belirlenmiştir. Her iki çeşitte de kontrol $(0.0 \mathrm{mg} \mathrm{B} \mathrm{kg-}$ $\left.{ }^{1}\right)$ bitkisi sırasıyla 0,83 ve $0,93 \mathrm{~g}^{\text {bitki }^{-1}}$ iken topraktan 2,5 mg B kg-1 uygulamasıyla kuru madde verimleri artarak sirasıyla 0,99 ve $1,10 \mathrm{~g} / \mathrm{bitki}$ olmuştur. Yüksek doz 10,0 mg B kg-1 uygulamasıyla da kuru madde veriminde belirgin azalmalar tespit edilmiştir (Çizelge 2). Sera koşullarında yapılan gözlemler neticesinde toprakta 2,5 ve $5,0 \mathrm{mg} \mathrm{B} \mathrm{kg}^{-1}$ uygulamaları altında her iki çeşitte de toksik etki gözlenmez (Şekil 1) iken, $10.0 \quad \mathrm{mg} \quad \mathrm{B} \quad \mathrm{kg}^{-1}$ uygulamaları altında çilekte toksik etkiler görülmüştür (Şekil 2).

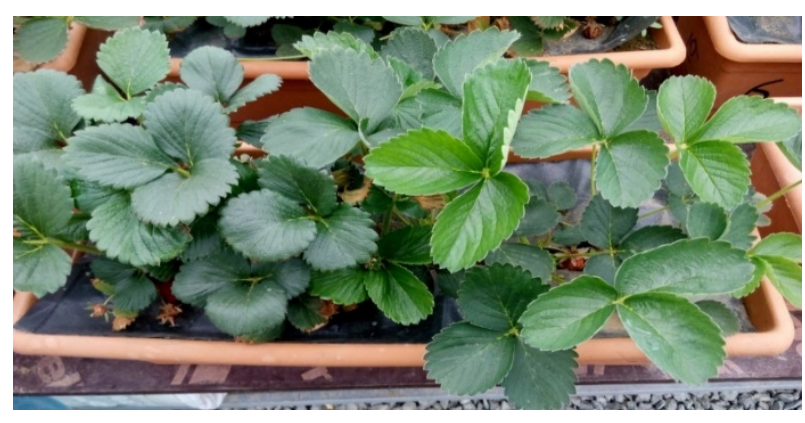

Şekil 1. Camarosa ve Sweet Charlie çilek çeşitlerinin $5.0 \mathrm{mg}$ $\mathrm{B} \mathrm{kg}{ }^{-1}$ uygulaması altında genel görünümü.

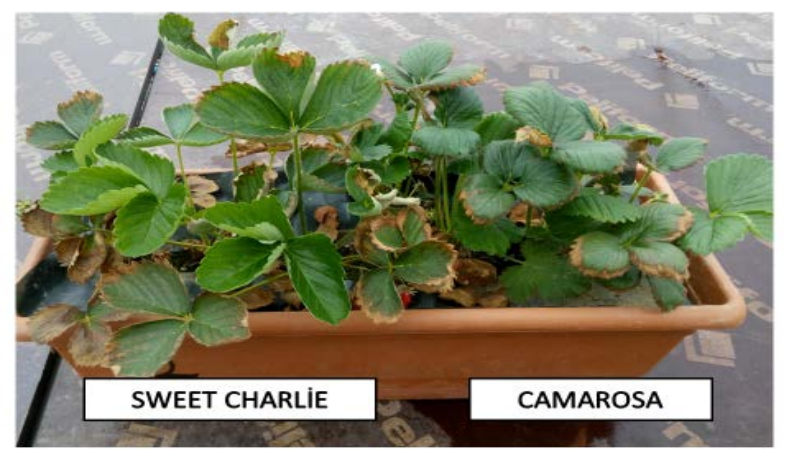

Şekil 2. Camarosa ve Sweet Charlie çilek çeşitlerinin 10.0 mg B kg-1 uygulaması altında toksik etkisi.
Her iki çeşitte de 10,0 mg kg-1 B uygulamasında kuru madde verimi azalmış olup düşük sayıda olsa da meyve verimi gerçekleşmiştir. Fakat oluşan meyveler düşük doz B uygulamasına göre küçük olmuştur.

\section{Bozuk Şekilli Meyve Oluşumu}

Bor konsantrasyonu yetersiz toprakta $(0,05 \mathrm{mg} \mathrm{B} \mathrm{kg-}$ 1) olan toprakta Camarosa ve Sweet Charlie çilek çeşitlerine artan $\left(0.0,2.5,5.0\right.$ ve $\left.10.0 \mathrm{mg} \mathrm{B} \mathrm{kg}^{-1}\right)$ dozlarda B uygulaması altında yetiştirilen çileklerin yeşil aksam B konsantrasyonları ve meyvelerinde farklılıkların olduğu saptanmıştır.

Hiç B uygulanmayan kontrol bitkisinde Camarosa çeşidinde yeşil aksam B konsantrasyonu 18,2 iken swet charlie çeşidinde 20,2 $\mathrm{mg} \mathrm{kg}^{-1}$ düzeyinde $B$ olduğu ve bu değerlerin Jones ve ark., (1991) tarafından çilek için belirlenen kritik sınır değere göre "az" olarak sınıflandırılmıştır.

Yapraklarında yetersiz B bulunan Sweet Charlie çilek çeşidinde bozuk şekilli meyveler oluşmuştur (Şekil 3).

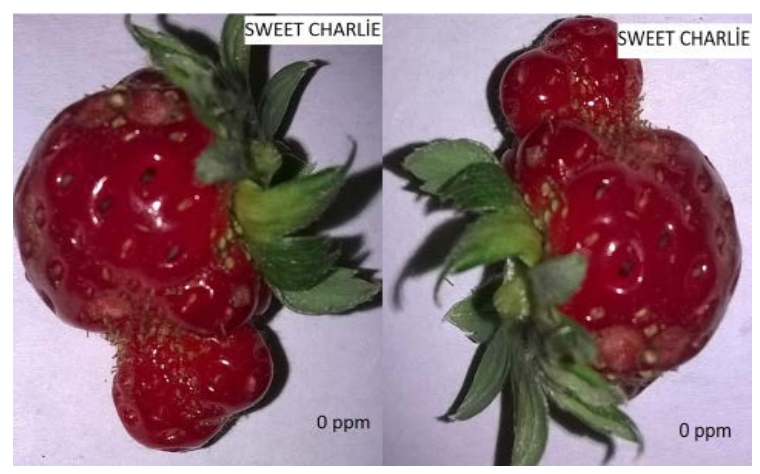

Şekil 3. Kontrol parsellerinde yetiştirilen Sweet Charlie çilek çeşitlerinde bozuk şekilli meyve oluşumu.

Jones ve ark., (1991)'e göre yapraklardaki B konsantrasyonu 25-30 mg kg-1 olduğunda yeterli iken 50 mg kg-1'den fazla olduğunda yüksek olarak sınıflandırılmaktadır. B bakımından yetersiz olan toprağa 2,5 ve $5,0 \mathrm{mg} \mathrm{kg}^{-1} \mathrm{~B}$ uygulamasında sırasıyla yeşil aksam B konsantrasyonu Camarosa çeşidinde 64,9 ve 83,7 iken Sweet Charlie çeşidinde bu değerler 47,8 ve $118,1 \mathrm{mg} \mathrm{kg}^{-1}$ düzeyinde olmuştur (Çizelge 3). Kritik yaprak sınır değerlere göre $50 \mathrm{mg} \mathrm{kg-1'den} \mathrm{fazla} \mathrm{olduğunda} \mathrm{yüksek}$ sayılmasına rağmen her iki çeşitte de herhangi bir toksik etki gözlenmemiş olup yeşil aksam kuru madde verimi de artmıştır. 
Çizelge 2. Artan dozlarda (0, 2.5, 5.0, $\left.10.0 \mathrm{mg} \mathrm{B} \mathrm{kg}^{-1}\right)$ B uygulamaları altında Camarosa ve Sweet Charlie çilek çeşitlerinin yeşil aksam kuru madde verimleri ( $\mathrm{g}$ bitki ${ }^{-1}$ )

\begin{tabular}{ccccccc}
\hline Uygulama B Dozları & \multicolumn{3}{c}{ Camarosa } & \multicolumn{3}{c}{ Sweet Charlie } \\
\hline $0 \mathrm{mg} \mathrm{B} \mathrm{kg}^{-1}$ & 0.83 & \pm & 0.06 & 0.93 & \pm & 0.06 \\
$2.5 \mathrm{mg} \mathrm{B} \mathrm{kg}^{-1}$ & 0.99 & \pm & 0.07 & 1.10 & \pm & 0.05 \\
$5.0 \mathrm{mg} \mathrm{B} \mathrm{kg}^{-1}$ & 1.09 & \pm & 0.05 & 1.07 & \pm & 0.06 \\
$10.0 \mathrm{mg} \mathrm{B} \mathrm{kg}^{-1}$ & 0.62 & \pm & 0.05 & 0.61 & \pm & 0.05 \\
\hline
\end{tabular}

Topraktan 2,5 ve 5,0 mg B kg-1 uygulaması altında yetiştirilen Sweet Charlie çileklerin meyveleri normal görünümde olduğu ve $5,0 \mathrm{mg} \quad \mathrm{B} \quad \mathrm{kg}^{-1}$ uygulamasında meyvelerin ideal görünümü elde edilmiştir (Şekil 4).

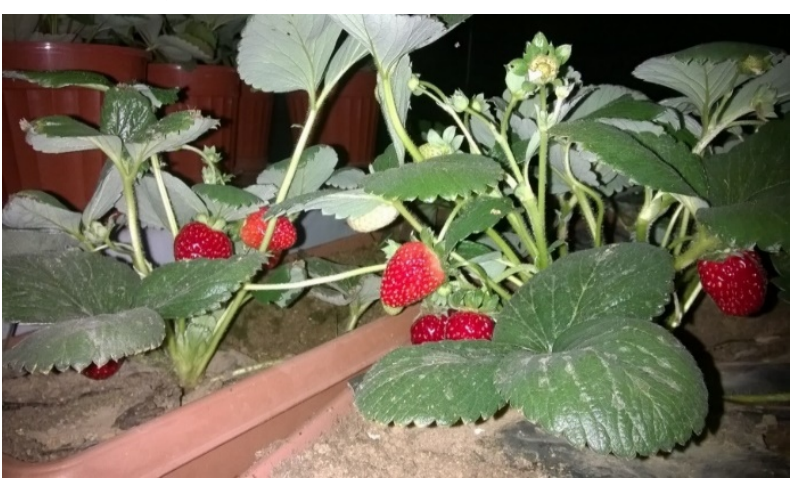

Şekil 4. Sweet Charlie çilek çeşitlerinin $5.0 \mathrm{mg} \mathrm{B} \mathrm{kg-1}$ uygulaması altında meyve görünümü.

Hiç B uygulanmayan kontrol saksında ve 5,0 mg B $\mathrm{kg}^{-1}$ uygulaması altında yetiștirilen Sweet Charlie çileklerinin görünümü Şekil 5'de verilmiştir.

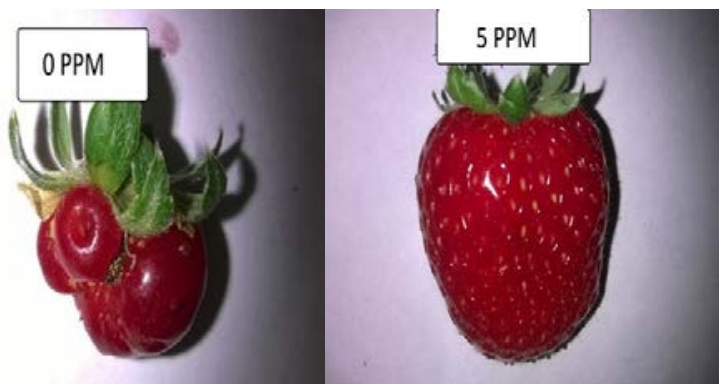

Şekil 5. Sweet Charlie çilek çeşitlerinin kontrol ve $5.0 \mathrm{mg} \mathrm{B}$ $\mathrm{kg}^{-1}$ uygulaması altında meyve görünümü.

Ayrıca, Camarosa çeşidinin B alım kapasitesi daha yüksek olduğu ve Sweet Charlie çeșidine göre daha dayanıksız olduğu da belirlenmiștir. Çilek çeșitlerine

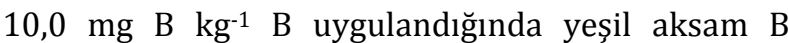
konsatrasyonları kontrole göre Camarosa çilek çeşidinde sırasıyla 334,8 olmuş ve toksik etki göstermiştir. Sweet Charlie çeşidinde ise kontrol 20,2 iken $10.0 \mathrm{mg} \mathrm{B} \mathrm{kg}^{-1}$ uygulamalarında 243,8 mg $B \mathrm{~kg}^{-1}$ düzeyine kadar yükselmiştir (Çizelge 3).
Topraktan artan (Kontrol, 2.5, 5.0 ve $10.0 \mathrm{mg} \mathrm{B} \mathrm{kg}^{-1}$ ) dozlarda B uygulanmasıyla yeşil aksam B konsantrasyonlarındaki artışa paralel olarak $P, K$ ve Zn konsantrasyonlarında da artışların olmasına karşın toplam $\mathrm{N}$ ve Ca miktarlarında azalmaların olduğu saptanmıştır (Çizelge 3).

\section{Meyve sayısı ve ağırlığı}

Bor bakımından yetersiz olan toprağa $\operatorname{artan}(0.0,2.5$, 5.0 ve $10.0 \mathrm{mg} \mathrm{B} \mathrm{kg}^{-1}$ ) dozlarda topraktan B uygulanmasıyla Camarosa ve Sweet Charlie çilek çeşitlerinin bitki başına verdikleri meyveler ile bir meyvenin ağırlıklarında farklılıkların olduğu saptanmıştır (Çizelge 4). Camarosa çilek çeşidinin kontrol uygulamasında bitki bașına 17 adet çilek meyvesi olușmuștur. Topraktan 2,5 ve $5,0 \mathrm{mg} \mathrm{B} \mathrm{kg}^{-1}$ uygulanmasıyla bu sayının sırasıyla 24 ve 28 olduğu belirlenmiştir. Sweet Charlie çeşidinde en düşük meyve sayısı kontrolde 19 iken en yüksek meyve sayısı 5,0 mg B kg-1 uygulamasında 31 adet meyve verdiği tespit edilmiştir. Ayrıca her iki çeşitte de yüksek doz 10,0 mg B kg-1 uygulanmasıyla meyve ağırlıklarında azalmaları olduğu bulunmuştur.

\section{Tartışma}

$\mathrm{Bu}$ araştırmada bor bakımından noksan (toprak $\mathrm{B}$ konsantrasyonu 0,05 mg $\mathrm{kg}^{-1}$ ) bir toprakta artan dozlarda bor gübrelemesinin camaraso ve Sweet Charlie çilek çeşitlerinin yaprak mineral element konsantrasyonları, bozuk şekilli meyve oluşumları, bitki başına meyve sayısı ve meyve ağırlıkları üzerine olan etkileri belirlenmiştir. Bor'ca noksan olan topraklarda yetiştirilen çileklerin yeterince B ile beslenememelerinden dolayı tozlanma ve döllenmenin yeterli olmamasına neden olmaktadır (Ariza ve ark., 2011). Bor'un bitkilerdeki eksiklik ve fazlalık sınırları birbirlerine çok yayındır (Gupta, 1979). Özellikle çilek bitkisinin yapraklarında B konsantrasyon sınır değerleri birbirine çok yakındır. Buna göre, yapraklarda $18-22 \mathrm{mg} \mathrm{kg}^{-1}$ olduğunda yetersiz, 25-30 mg kg-1 B olduğunda yeterli ve $50 \mathrm{mg}$ $\mathrm{kg}^{-1}$ 'den yüksek olduğunda fazla olarak sınıflandırılmıştır (Jones ve ark., 1991). 
Çizelge 3. Artan dozlarda (Kontrol, 2.5, 5.0, 10.0 ve $20.0 \mathrm{mg} \mathrm{B} \mathrm{kg}^{-1}$ ) B uygulamaları altında Camarosa ve Sweet Charlie çilek çeşitlerinin yeşil aksam makro ve mikro element konsantrasyonu

\begin{tabular}{|c|c|c|c|c|c|c|c|c|c|c|c|c|}
\hline \multirow{3}{*}{$\frac{\text { Uygulamalar. Bor Dozları }}{0 \mathrm{mg} \mathrm{B} \mathrm{kg}^{-1}}$} & \multicolumn{6}{|c|}{$\mathrm{N}(\%)$} & \multicolumn{6}{|c|}{$\mathrm{B}\left(\mathrm{mg} \mathrm{kg}^{-1}\right)$} \\
\hline & \multicolumn{3}{|c|}{ Camarosa } & \multicolumn{3}{|c|}{ Sweet Charlie } & \multicolumn{3}{|c|}{ Camarosa } & \multicolumn{3}{|c|}{ Sweet Charlie } \\
\hline & 3.44 & \pm & 0.10 & 3.38 & \pm & 0.06 & 18.2 & \pm & 3.2 & 20.2 & \pm & 3.0 \\
\hline $2.5 \mathrm{mg} \mathrm{B} \mathrm{kg}^{-1}$ & 3.20 & \pm & 0.05 & 3.17 & \pm & 0.07 & 64.9 & \pm & 4.4 & 47.8 & \pm & 7.4 \\
\hline $5.0 \mathrm{mg} \mathrm{B} \mathrm{kg}^{-1}$ & 2.95 & \pm & 0.04 & 2.93 & \pm & 0.06 & 83.7 & \pm & 5.1 & 118.1 & \pm & 17.7 \\
\hline \multirow[t]{2}{*}{$10.0 \mathrm{mg} \mathrm{B} \mathrm{kg}^{-1}$} & 2.84 & \pm & 0.04 & 2.83 & \pm & 0.03 & 334.8 & \pm & 24.8 & 243.8 & \pm & 28.0 \\
\hline & \multicolumn{6}{|c|}{$\mathrm{P}(\%)$} & \multicolumn{6}{|c|}{$\mathrm{Fe}\left(\mathrm{mg} \mathrm{kg}^{-1}\right)$} \\
\hline $0 \mathrm{mg} \mathrm{B} \mathrm{kg}^{-1}$ & 0.42 & \pm & 0.02 & 0.31 & \pm & 0.02 & 140.6 & \pm & 5.9 & 132.6 & \pm & 0.4 \\
\hline $2.5 \mathrm{mg} \mathrm{B} \mathrm{kg}^{-1}$ & 0.51 & \pm & 0.03 & 0.43 & \pm & 0.02 & 188.0 & \pm & 10.0 & 151.2 & \pm & 1.7 \\
\hline $5.0 \mathrm{mg} \mathrm{B} \mathrm{kg}^{-1}$ & 0.59 & \pm & 0.02 & 0.50 & \pm & 0.05 & 206.7 & \pm & 12.5 & 173.5 & \pm & 24.9 \\
\hline \multirow[t]{2}{*}{$10.0 \mathrm{mg} \mathrm{B} \mathrm{kg}^{-1}$} & 0.65 & \pm & 0.02 & 0.55 & \pm & 0.06 & 269.1 & \pm & 16.4 & 170.8 & \pm & 32.0 \\
\hline & \multicolumn{6}{|c|}{$\mathrm{Ca}(\%)$} & \multicolumn{6}{|c|}{$\mathrm{Zn}\left(\mathrm{mg} \mathrm{kg}^{-1}\right)$} \\
\hline $0 \mathrm{mg} \mathrm{B} \mathrm{kg}^{-1}$ & 1.78 & \pm & 0.13 & 1.81 & \pm & 0.06 & 23.1 & \pm & 2.4 & 22.6 & \pm & 0.8 \\
\hline $2.5 \mathrm{mg} \mathrm{B} \mathrm{kg}^{-1}$ & 1.47 & \pm & 0.04 & 1.43 & \pm & 0.04 & 28.1 & \pm & 0.6 & 28.1 & \pm & 0.4 \\
\hline $5.0 \mathrm{mg} \mathrm{B} \mathrm{kg}^{-1}$ & 1.40 & \pm & 0.02 & 1.45 & \pm & 0.16 & 28.3 & \pm & 2.5 & 31.1 & \pm & 2.8 \\
\hline \multirow[t]{2}{*}{$10.0 \mathrm{mg} \mathrm{B} \mathrm{kg}^{-1}$} & 1.40 & \pm & 0.04 & 1.66 & \pm & 0.21 & 32.2 & \pm & 1.4 & 31.6 & \pm & 1.3 \\
\hline & \multicolumn{6}{|c|}{ K (\%) } & \multicolumn{6}{|c|}{$\mathrm{Cu}\left(\mathrm{mg} \mathrm{kg}^{-1}\right)$} \\
\hline $0 \mathrm{mg} \mathrm{B} \mathrm{kg}^{-1}$ & 1.55 & \pm & 0.04 & 1.56 & \pm & 0.05 & 3.79 & \pm & 0.36 & 5.25 & \pm & 0.39 \\
\hline $2.5 \mathrm{mg} \mathrm{B} \mathrm{kg}^{-1}$ & 1.60 & \pm & 0.04 & 1.69 & \pm & 0.04 & 4.57 & \pm & 0.52 & 4.22 & \pm & 0.18 \\
\hline $5.0 \mathrm{mg} \mathrm{B} \mathrm{kg}^{-1}$ & 1.68 & \pm & 0.02 & 2.01 & \pm & 0.04 & 4.20 & \pm & 0.20 & 5.72 & \pm & 0.92 \\
\hline \multirow[t]{2}{*}{$10.0 \mathrm{mg} \mathrm{B} \mathrm{kg}^{-1}$} & 1.69 & \pm & 0.04 & 2.05 & \pm & 0.08 & 4.45 & \pm & 1.35 & 2.57 & \pm & 0.65 \\
\hline & \multicolumn{6}{|c|}{$\mathrm{Mg}(\%)$} & \multicolumn{6}{|c|}{ Mn (mg kg-1) } \\
\hline $0 \mathrm{mg} \mathrm{B} \mathrm{kg}^{-1}$ & 0.68 & \pm & 0.06 & 0.57 & \pm & 0.01 & 108.7 & \pm & 11.6 & 130.8 & \pm & 26.7 \\
\hline $2.5 \mathrm{mg} \mathrm{B} \mathrm{kg}^{-1}$ & 0.60 & \pm & 0.02 & 0.57 & \pm & 0.03 & 92.7 & \pm & 2.1 & 150.3 & \pm & 21.1 \\
\hline $5.0 \mathrm{mg} \mathrm{B} \mathrm{kg}^{-1}$ & 0.67 & \pm & 0.02 & 0.60 & \pm & 0.07 & 84.3 & \pm & 5.5 & 149.4 & \pm & 23.9 \\
\hline $10.0 \mathrm{mg} \mathrm{B} \mathrm{kg}^{-1}$ & 0.75 & \pm & 0.12 & 0.62 & \pm & 0.07 & 75.3 & \pm & 3.8 & 160.9 & \pm & 22.7 \\
\hline
\end{tabular}

Çizelge 4. Artan dozlarda $\left(0,2.5,5.0,10.0 \mathrm{mg} \mathrm{B} \mathrm{kg}^{-1}\right)$ B uygulamaları altında Camarosa ve Sweet Charlie çilek çeşitlerinin bitki bașına meyve sayısı ve bir meyvenin ağırlı̆̆ı

\begin{tabular}{|c|c|c|c|c|c|c|c|c|c|c|c|c|}
\hline \multirow{3}{*}{$\frac{\text { Uygulama B Dozları }}{0 \mathrm{mg} \mathrm{B} \mathrm{kg}^{-1}}$} & \multicolumn{6}{|c|}{ Meyve sayısı (meyve sayısı/bitki) } & \multicolumn{6}{|c|}{ Meyve ağırlı̆̆ı (g/meyve) } \\
\hline & \multicolumn{3}{|c|}{ Camarosa } & \multicolumn{3}{|c|}{ Sweet Charlie } & \multicolumn{3}{|c|}{ Camarosa } & \multicolumn{3}{|c|}{ Sweet Charlie } \\
\hline & 17 & \pm & 2 & 19 & \pm & 2 & 10 & \pm & 0.9 & 9 & \pm & 0.9 \\
\hline $2.5 \mathrm{mg} \mathrm{B} \mathrm{kg-1}^{-1}$ & 24 & \pm & 2 & 27 & \pm & 2 & 12 & \pm & 0.3 & 9 & \pm & 0.8 \\
\hline $5.0 \mathrm{mg} \mathrm{B} \mathrm{kg}^{-1}$ & 28 & \pm & 1 & 31 & \pm & 2 & 12 & \pm & 0.8 & 10 & \pm & 0.8 \\
\hline $10.0 \mathrm{mg} \mathrm{B} \mathrm{kg}^{-1}$ & 23 & \pm & 7 & 18 & \pm & 1 & 8 & \pm & 0.4 & 7 & \pm & 0.2 \\
\hline
\end{tabular}

Çilek bitkisinin düşük miktarlarda B’a gereksinim duymasından dolayı genellikle çilekte B uygulamalarının yapraktan yapılması topraktan uygulamaya tercih edilmektedir. $\mathrm{Bu}$ araştırmada yetersiz B içeren toprağa topraktan B uygulamasının etkileri belirlenmiştir. Sera koşullarında yetersiz B konsantrasyonuna sahip olan toprak kullanılarak saksı denemesinde kısa gün çilek çeşitlerinden kontrol uygulamalarındaki Camarosa ve Sweet Charlie çilek çeşitlerinin yapraklarında 18,2 ve 20,2 $\mathrm{mg} \mathrm{kg}^{-1} \mathrm{~B}$ konsantrasyonu olduğu ve bu miktarında B noksanlığı nedeniyle, bozuk şekilli meyveler oluşmasını teşvik ettiği belirlenmiştir.

Yetersiz B konsantrasyonuna sahip toprakta yetiştirilen çileklerin meyvelerinin bozuk şekilli olmas birçok araştırıcının bulgularıyla benzerlik göstermektedir. Farklı araştırıcılar tarafından B noksan topraklarda yetiştirilen çileklerde polen oluşumunun yeterince gerçekleşmediği, polen tüp büyümesinin yetersiz olduğu ve meyve büyümesinin azaldığı belirlenmiştir (Leiten, 1989; Lieten, 2002; Sharma ve Sharma, 2004). Yapılan bu araștırma düşük (2,5 mg B kg-1 toprak) doz B uygulamasıyla çilek bitkisi $\mathrm{B}$ bakımından yeterli beslendiği ve bunun sonucunda da bozuk şekilli meyve oluşumunda azalmaların olduğu bulunmuştur. B uygulamalarının bozuk şekilli meyve oluşumunu azaltmasına yönelik elde ettiğimiz bulgular birçok araştırıcının çalışmalarıyla benzerlik göstermektedir. Örneğin, Sharma ve ark., (2006) çileklerde $\mathrm{Ca}+\mathrm{B}$ uygulamalarının bozuk şekilli meyve oluşumlarını azalttığını bildirmiştir. Çilekte Ca veya $\mathrm{Ca}+\mathrm{B}$ uygulamalarının polen tüpü büyümesine, meyve tutumuna ve meyve büyümesi üzerine pozitif olarak etki ettiğini ve bunun sonucunda da bozuk şekilli meyve oluşumlarının azaldığı bildirilmiştir (Wojcik ve Lewandowski, 2003; Naradisorn ve ark., 2006). Benzer bir bulguda Singh ve ark., (2007) tarafından chandler çilek çeşidinde $\mathrm{B}, \mathrm{Ca}$ ve $\mathrm{Ca}+\mathrm{B}$ uygulamaları altında yetiştirdiği çilekte kontrol 
uygulamasında \% 12.4 oranında ve B uygulamasıyla bozuk şekilli meyve oluşumunun azaldığını bildirmiştir.

Yapılan bu araștırmada düşük (2,5 $\mathrm{mg} \mathrm{B} \mathrm{kg}^{-1}$ toprak) doz B uygulamasıyla çilek yapraklarında B konsantrasyonu Camarosa ve Sweet Charlie çeşitlerinde sirasıyla 64,9 ve $47,8 \mathrm{mg} \mathrm{kg}^{-1}$ olduğu ve B ile yeterli beslendiği bulunmuştur. Yüksek $(10,0$ mg B kg-1 toprak) dozda B uygulamasında çilek yapraklarında B konsantrasyonu her iki çeşitte de oldukça fazla miktarda birikmiș olup sırasıyla 334,8 ve $243,8 \mathrm{mg} \mathrm{kg}^{-1}$ bulunduğu ve bunun sonucunda bitkide toksik etkisinin olduğu saptanmıştır. Karabıyık ve ark., (2016) tarafından Rubygem çilek çeşidinde yapraktan B uygulamasıyla bozuk şekilli meyve oluşumunun önemli ölçüde azaldığı bildirilmiştir.

Elde ettiğimiz diğer önemli bir bulgu da artan dozlarda B uygulamasıyla bitki başına düşen meyve sayısında artış olmasıdır. Düşük doz B uygulamasıyla kontrole göre bitki başına alınan meyve sayısında artış olduğu yüksek doz B uygulamasıyla kontrole göre düșüș olduğu belirlenmiștir. Yüksek doz B uygulamasında elde edilen meyvelerin ağırlıklarında azalmaların olduğu saptanmıştır. Hiç B uygulanmayan kontrol bitkilerinde elde edilen meyve ağırlıkları $10 \mathrm{~g}$ ve $9 \mathrm{~g}$ iken yüksek (10,0 mg B $\mathrm{kg}^{-1}$ toprak) doz B uygulamasında bitkide toksik etkilerinin görüldüğü ve buna bağlı olarak oluşan meyveler küçülmüştür. Meyvelerin küçülmesine bağlı olarak meyve ağırlıkları yaklaşık \% 50 oranında azalarak sirasıyla 7 ve 6 g olarak elde edilmiştir.

$\mathrm{Bu}$ araștırmada, artan dozlarda B uygulanmasıyla çilek yapraklarının mineral element konsantrasyonlarında da farklılıkların olduğu bulunmuştur. Bor uygulamasıyla yaprakların toplam $\mathrm{N}$ ve Ca konsantrasyonlarında azalma toplam $\mathrm{P}, \mathrm{K}$ ve Zn konsantrasyonlarında artışların olduğu belirlenmiştir. Elde edilen bulgulara benzer sonuçlar Sarıdaş ve ark., (2016) ve Esringü ve ark., (2011) tarafından yapılan araştırmalarda da bulunmuştur. Örneğin, Sarıdaş ve ark., (2016) tarafından çilekte B uygulamasıyla yaprak $\mathrm{Ca}$ konsantrasyonunda azalmanın olduğu bildirilmiștir. Esringü ve ark., (2011) tarafından hektara 5,5 kg B uygulamasında çilek yapraklarında mineral komposizyonun değiştiğini ve $\mathrm{B}$ uygulamasıyla toplam $\mathrm{N}$ ve Ca'un azalmasına karşın; $\mathrm{P}, \mathrm{K}, \mathrm{Mn}, \mathrm{Zn}$ ve $\mathrm{Cu}$ konsantrasyonlarında artış olduğu bildirilmiştir.

\section{Sonuç}

Araştırma sonuçlarına göre üç önemli bulgu elde tespit edilmiştir.

I. Kısa gün bitkisi olan Camarosa ve Sweet Charlie çilek çeşitlerinin B noksan bir toprakta yetiştirildiklerinde bozuk şekilli meyveler vererek ekonomik kayıplara yol açtığı,

II. Düşük doz (2,5 mg B $\mathrm{kg}^{-1}$ toprak $)$ B gübrelemesi sonucunda yapraklarda yeterli miktarda B taşındığı ve bozuk şekilli meyve oluşumları önemli ölçüde giderildiği,

III. Yüksek doz (10,0 mg B kg-1 toprak) B gübrelemesinde yapraklarda toksik etki yaptığı ve oluşan meyvelerin küçük olduğu,

IV. Düşük doz (2,5 mg $\mathrm{B} \quad \mathrm{kg}^{-1}$ toprak $)$ B gübrelemesiyle yaprakların $\mathrm{P}, \mathrm{K}, \mathrm{Mn}, \mathrm{Zn}$ ve $\mathrm{Cu}$ elementlerini artırdığı,

V. Topraktan düşük doz (2,5 $\mathrm{mg} \mathrm{B} \mathrm{kg}^{-1}$ toprak) $B$ gübrelemesi sonucunda bitki başına düşen meyve sayısı ve meyve ağırlıklarını artırdığı belirlenmiştir.

$\mathrm{Bu}$ çalışmaların sonuçları B noksan olan alanlarda topraktan düşük miktarda B gübrelemesinin çilek yetiştiriciliğinde bozuk şekilli meyve oluşumlarını azaltılması üzerine önemli etkisinin olduğu saptanmiştır.

\section{Teşekkür}

$\mathrm{Bu}$ çalışma Ordu Üniversitesi Bilimsel Araştırma Projeleri tarafindan desteklenmiştir (Proje No: AR1502).

\section{Kaynaklar}

Allison, L.E., Moodie, C.D. 1965. Carbonate. In: CA Black et al. (eds.) Methods of soil analysis, Part 2, Agronomy Series, Am. Soc. of Agron., USA, 9:1379-1400.

Anonim, 2012. Organik tarım. Tarım ve Köyişleri Bakanlığı. Ülkemizde organik çilek yetiştiriciliği yapan iller ve üretim miktarları. www.tarım.gov.tr.

Ariza, M. T., C. Soria, J. J. Medina, E. Martinez-Ferri, 2011. Fruit misshapen in strawberry cultivars (fragaria $\mathrm{x}$ ananassa) is related to achenes functionality. Annals of Applied Biology.

Bingham, F.T. 1982. Boron. In: Page, A.L.(Ed.), Methods of soil analysis. Part 2, Am. Soc. Argon. Madison, WI. 431-448.

Boss, C. B., Fredeen K. J. 2004. Concept instrumentation and techniques in inductively coupled plasma optical emission spectroscopy, Perkin-Elmer, Bridgeport Avenue Shelton. 
Bouyoucous, G.J. 1951. A recalibration of hydrometer method for making mechanical analysis of soils. Agronomy Journal, 43: 434-437.

Bray, R. H., Kurtz, L.T. 1945. Determination of total, organic and available forms of phosphorus in soils. Soil science.59:39-45.

Bremner, J.M. 1965. Total nitrogen methods of soil analysis. part 2. chemical and microbiological properties. Ed. C.A. Black. Amer. Soc. of Agron. Inc. Pub. Agron. Series. No: 9, Madison, Wisconsin, U.S.A., 1149-1178.

Brown, P.H., Bellaloui., N., Wimmer, M.A., Bassil, E.S., Ruiz, J., Hu, H., Pfeffer H, Dannel., F, Römheld, V. 2002. Boron in plant biology. Plant Biol 4, 205-223.

Demirsoy, L., Öztürk, A., ve Serçe, S. 2012. Çileklerde (Fragaria) çiçeklenme ile fotoperiyot arasındaki İlişkiler. Anadolu Tarım Bilim Dergisi, Samsun; 110-119.

Esringü, A., Turan, M., Gunes, A., Eșitken, A., Sambo, P. 2011. Boron application improves on yield and chemical composition of strawberry. Acta Agriculturae Scandinavica, Section B - Soil \& Plant Science. 61: 245_252.

FAO, 2013. www.fao.org. Food and Agriculture Statistics.

Gupta, U.C. 1979. Boron nutrition of crops. Adv. Agron. 31, 273-307.

Gupta, U.C., Jame, Y.W., Campbell, C.A., Leyshon, A.J., Nicholaichuk, W.1985. Boron toxicity and deficiency, Can. J. Soil Sci., 65: 381-409.

Jones, J.R., Wolf, B., Mills, H.A. 1991. Plant analysis handbook. Micro Macro Publishing.

Karabıyık, Ş., Sarıdaş, M.A., Eti, S., Kargı, S.P. 2016. Rubygem çilek çeşidinde bor ve kalsiyum uygulamalarının bozuk şekilli meyve oluşumu ve çiçek tozu kalitesine etkisi. Uluslararası tarımda bor sempozyumu bildiriler kitabı. 77-78.

Kașka, N., Yıldız, A.I., Paydaș, S., Biçici, M., Türemiș, N., Küden, A. 1986. Türkiye için yeni bazı çilek çeşitlerinin Adana'da yaz ve kış dikim sistemleriyle örtü altında yetiștiriciliğinin verim, kalite ve erkencilik üzerine etkileri. Doğa Bilim Dergisi, Seri D2, 10(1): 84-102.

Lieten, F. 1989. Strawberry: albinism, a new physiological disorder. Fruitteelt 2: 39-41.

Lieten, P. 2002. Boron deficiency of strawberries grown in substrate culture. Acta Hortic. 567, 451-454.

Lindsay, W.L., Norvell, W.A. 1978. Development of a DTPA soil test for zinc, iron, manganese and copper. Soil Sci. Amer. Jour., 42(3): 421-428.
Marschner, H. 1995. Mineral Nutrition of Higher Plants. 2nd edn. Academic press. San Diego, pp. 379-396.

Naradisorn, M., Klieber, A., Sedgley, M., Scott, E., Able, A.J., 2006. Effect of preharvest calcium application on grey mould development and post-harvest quality in strawberries. Acta Hort. 708: 147-150.

Pratt P. F. 1965. Methods of Soil Analysis Part 2. Chemical and microbiolojical properties. Ed. C.A. Black. Amer. Soc. Agr. Inc. Publisher Agronomy Series, 9: 999- 1034.

Richards, L.A. .1954. Diagnosis and Improvement Saline and Alkaline Soils. U.S. Dep. Agr. Handbook 60.

Sarıdaş, M.A., Nogay, G., Attar, Ş.H., Kargı, S.P., Kafkas, E. 2016. Çileklerde bor ve kalsiyum uygulamalarının meyve kalitesi ve yaprak mineral içerikleri üzerine etkileri. Uluslararası tarımda bor sempozyumu bildiriler kitabı. pp: 91-92.

Sharma, R.R., Krishna, H., Patel, V.B., Dahuja, A., Singh, R., 2006. Fruit calcium content and lipoxygenase activity in relation to albinism disorder in strawberry. Sci. Hortic. 107: 150-154.

Sharma, R.R., Sharma, V.P., Pandey, S.N., 2004. Mulching influences plant growth and albinism disorder in strawberry under subtropical climate. Acta Hortic. 662: 187-191.

Shorrocks, V. M. 1997. The occurrence and correction of boron deficiency. Plant and Soil, 193: 121_148.

Singh, R., Sharma, R. R., Tyagi, S. K. 2007. Pre-harvest foliar application of calcium and boron influences physiological disorders, fruit yield and quality of strawberry (Fragaria x ananassa Duch.). Scientia horticulturae, 112(2): 215-220.

Stewart, P. J. and Folta, K. M. 2010. A review of photoperiodic flowering research in strawberry (Fragaria spp.). Critical reviews in plant science, 29(1): 1-13.

Türemiş, N. 2003. Yeni bazı çilek çeşitlerinin Kıbrıs koşullarındaki adaptasyonu. Kktc/Tagep 5.2.3.4 Nolu Proje Sonuç Raporu.

Walkey, A., Black, L. A. 1934. An examination of the Degtjareff method for determining soil organic matter and proposed modification of the chromic acit titration method. Soil sci. 37: 29-38.

Wojcik, P., Lewandowski, M. 2003. Effect of spray of calcium and boron on yield and quality of 'Elsanta' strawberry. Journal of Plant Nutrition, 3, 671_682. 